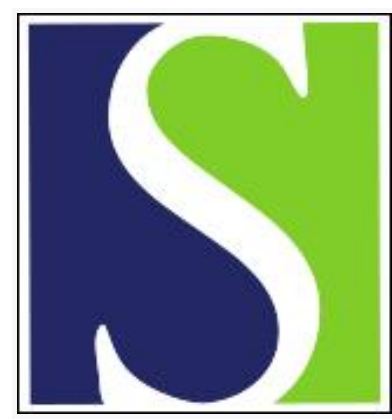

Scand J Work Environ Health 2018;44(6):647-657

https://doi.org/10.5271/sjweh.3745

Published online: 17 Jun 2018, Issue date: 01 Nov 2018

Indoor, outdoor, and night work and blood concentrations of vitamin $D$ and parathyroid hormone

by Daugaard S, Garde AH, Hansen ÅM, Vistisen HT, Rejnmark L, Kolstad HA

We observed lower 250HD and higher PTH concentrations among permanent but not rotating night workers compared with indoor workers. Furthermore, that 250HD levels increased significantly by increasing hours spent outdoors. Clinicians should be aware that vitamin $\mathrm{D}$ insufficiency may be more prevalent among permanent night workers and employers should consider the beneficial health effects of outdoor work.

Affiliation: Department of Occupational Medicine, Aarhus University Hospital, Aarhus, Denmark, Nørrebrogade 2c, 8000 Århus C, Denmark. stepde@rm.dk

Key terms: blood concentration; cross-sectional study; diet; indoor work; night work; occupation; occupational health; outdoor work; parathyroid hormone; risk factor; season; shift work; ultraviolet radiation; vitamin D

This article in PubMed: www.ncbi.nlm.nih.gov/pubmed/29909424 


\title{
Indoor, outdoor, and night work and blood concentrations of vitamin D and parathyroid hormone
}

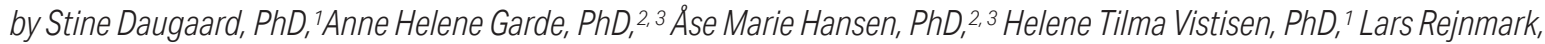 \\ PhD, ${ }^{4}$ Henrik Albert Kolstad, $P h D^{1}$
}

\begin{abstract}
Daugaard S, Garde AH, Hansen ÅM, Vistisen HT, Rejnmark L, Kolstad HA. Indoor, outdoor, and night work and blood concentrations of vitamin D and parathyroid hormone. Scand J Work Environ Health. 2018;44(60:647-657. doi:10.5271/ sjweh.3745
\end{abstract}

Objectives The aim of this study was to examine blood concentrations of 25-hydroxyvitamin D (25OHD) and parathyroid hormone (PTH) among indoor, outdoor, permanent and rotating night workers and the association with hours spent outdoors on and off work days.

Methods Blood samples were collected from 425 workers (162 indoor, 112 outdoor, 118 rotating night and 33 permanent night workers) throughout all seasons. Serum concentrations of 25 -hydroxyvitamin D (25OHD) and parathyroid hormone (PTH) were analyzed by isotope dilution liquid chromatography-tandem mass spectrometry (LC MS/MS) and an automated immune analyzer, respectively. Personal light exposure levels were continuously recorded and used to estimate hours spent outdoors (all workers).

Results Permanent night workers had 25.3\% (95\% CI 11.9-36.6) lower 25OHD concentration, 4.55 (95\% CI $1.39-14.94)$ higher odds of vitamin D insufficiency $(<50 \mathrm{nmol} / \mathrm{L})$ and $14.5 \%$ [95\% confidence interval (CI) 0.1-31.1] higher PTH concentration than indoor workers. Outdoor workers had similar 25OHD concentrations but 7.5\% (95\% CI -0.5-14.9) lower PTH concentration compared to indoor workers. Rotating night workers 25OHD and PTH concentrations did not differ from indoor workers. Concentration of 25OHD increased by $5.2 \%$ (95\% CI 1.1-9.5) per hour spent outdoor at workdays in the summer.

Conclusion Clinicians should be aware that vitamin D insufficiency may be more prevalent among permanent night workers and human resources should consider the positive effect of allowing workers to spend time outdoors during work hours.

Key terms cross-sectional study; diet; indoor work; occupation; occupational health; outdoor work; risk factor; season; shift work; ultraviolet radiation.

The importance of vitamin $\mathrm{D}$ in maintaining calcium homeostasis and skeletal health is well established (1). The anti-proliferative and immunomodulatory effects of vitamin D $(2,3)$ as well as the presence of vitamin $\mathrm{D}$ receptors in tissues not related to calcium metabolism (4) suggest that vitamin D has pleiotropic effects beyond calcium metabolism. Epidemiological studies have reported an association between low vitamin D and increased risks of extra skeletal diseases such as colorectal cancer $(5)$, cardiovascular disease $(6,7)$, diabetes (8), multiple sclerosis (9), and allergy (10). Permanent and rotating shift work has been associated with increased risk of cancer (11), diabetes (12-14) and fractures (15). Opposing, outdoor work has been inversely associated with cancer (16-18), multiple sclerosis $(19,20)$ and Parkinson's disease $(21-23)$. Though any causal relations remain to be established, vitamin $\mathrm{D}$ has repeatedly been suggested as a mediator of the observed associations $(20,21,24,25)$. With the exception of one study (29), previous research (26-28) have found higher 25-hydroxyvitamin D (25OHD) concentrations among outdoor than day workers. Permanent night work has been associated with lower 25OHD concentrations among female but not male night workers (30).

1 Department of Occupational Medicine, Danish Ramazinni Centre, Aarhus University Hospital, Aarhus, Denmark.

2 National Research Centre for the Working Environment, Copenhagen, Denmark.

3 Department of Public Health, Copenhagen University, Copenhagen, Denmark.

4 Department of Endocrinology and Internal Medicine, Aarhus University Hospital. Aarhus, Denmark.

Correspondence to: Stine Daugaard, Department of Occupational Medicine, Aarhus University Hospital, Aarhus, Denmark, Nørrebrogade 2c, 8000 Århus C, Denmark. [E-mail: stepde@rm.dk] 
Rotating night workers had lower 25OHD concentration compared to day workers in male and mixed populations (31-33). However, no difference between day and rotating night workers has also been found in male and mixed populations $(29,34,35)$.

Vitamin D is a fat-soluble pro-hormone mainly derived from synthesis by the skin upon exposure to ultraviolet $B$ radiation (UVB) from sunlight; only a minor part is obtained from foods such as milk, fish, and meat (36). In Denmark (latitude 55-56 ${ }^{\circ} \mathrm{N}$ ), vitamin D synthesis is only induced by UVB from March till September and summer sun exposure is important for vitamin D concentration around the year (37).

Vitamin D status is defined by plasma concentrations of 25OHD. The cut-off value to define vitamin D insufficiency in terms of skeletal outcomes is $50 \mathrm{nmol} / \mathrm{L} \mathrm{(38)}$. In terms of non-skeletal health outcomes it is suggested that a sufficient vitamin $\mathrm{D}$ status requires concentrations $>75-80 \mathrm{nmol} / \mathrm{L}$ (39). Importantly, the optimal $25 \mathrm{OHD}$ concentration in non-skeletal health outcomes has not yet been clarified (40). Vitamin D insufficiency is common worldwide, also in Denmark where studies have suggested a prevalence of vitamin D insufficiency as high as $52.2 \%$ among healthy adults (41).

Parathyroid hormone (PTH) concentrations are inversely correlated with $25 \mathrm{OHD}$ concentrations. A rise in PTH signals that insufficient 25OHD concentrations start to negatively affect bone metabolism (42). The 25OHD concentration at which PTH concentrations start to increase has substantial inter-individual variation. Independently of $25 \mathrm{OHD}$ concentrations, increased PTH concentrations have been associated with increased risk of fractures (43), cardiovascular disease (44), and overall mortality (45).

As vitamin D insufficiency is common, easily treatable and may have major health consequences for the individual, it is important to identify current risk factors for vitamin $\mathrm{D}$ insufficiency including the work environment. Low 25OHD concentrations in indoor and night workers may be explained by limited exposure to sunlight during work and leisure time, differences in intake of vitamin D supplement, dietary habits, or lifestyle factors. Furthermore to elucidate a possible mediation by $25 \mathrm{OHD}$ concentrations in epidemiological studies of night and outdoor work, knowledge of differences in $25 \mathrm{OHD}$ concentration by job type is crucial.

The aim of this study was to examine blood concentrations of 25OHD and PTH among indoor, outdoor, permanent and rotating night workers and the association with hours spent outdoors on work days and days off.

\section{Methods}

\section{Study set up}

Participants were recruited through employers and public advertisements in magazines and on webpages aimed at recruiting an equal numbers of indoor, outdoor and night workers.

A research assistant met the participants at their place of work, provided instructions, handed out a questionnaire to get data on background characteristics and collected a blood sample. For continuous measurement of light levels, participants wore a light recorder during seven days both at and off work. Data was collected from March 2012 until May 2013. All participants gave written informed consent and the Danish Data Protection Agency (J.nr. 2011-41-6850) and the Central Denmark Region Committee on Health Research Ethics (M-20110214) approved the study. Further details of the study design are presented elsewhere (46).

\section{Population}

A total of 535 participants were recruited and 459 provided a blood sample. Samples of 8 participants could not be analyzed due to insufficient blood volume. Of the participants, 26 were excluded due to medical conditions or treatment potentially affecting calcium homeostasis and vitamin D metabolism: use of thiazide diuretics $(\mathrm{N}=10)$, pregnancy $(\mathrm{N}=7)$, suspected primary hyperparathyroidism (serum calcium and plasma PTH above normal) $(\mathrm{N}=2)$, anticonvulsants $(\mathrm{N}=1)$, systemic glucocorticoids $(\mathrm{N}=1)$, estimated glomerular filtration rate $(\mathrm{eGFR})<60 \mathrm{ml} / \mathrm{min}$ and metastasized breast cancer $(\mathrm{N}=1)$. The final population comprised 425 participants with complete confounder information except for 12 participants with missing information on body mass index (BMI).

Indoor workers were defined as those working daytime only and working $\leq 9$ hours outdoors per week during the summer (June-August) $(\mathrm{N}=162)$. The majority $(72.8 \%)$ of the indoor workers never worked outdoors, $12.4 \%$ worked outdoors $1-4$ hours/week and $14.8 \%$ reported 5-9 outdoor work hours/week. Outdoor workers were defined as working daytime only and outdoors $>9$ hours/week during the summer $(\mathrm{N}=112)$. Of these, $31.3 \%$ worked outdoors 10-19 hours a week, 41.1\% worked 20-29 hours/week, and 27.7\% worked 30-37 hours/week. Night workers were defined as working $>3$ hours between 00:00-05:00 hours on a permanent $(\mathrm{N}=33)$ or rotating shift work basis $(\mathrm{N}=118)(47)$. Classification of participants into the above job groups was based on questionnaire data.

To define vitamin $\mathrm{D}$ insufficiency, we chose a cut-off value at $50 \mathrm{nmol} / \mathrm{L}$, which is the $25 \mathrm{OHD}$ concentration 
recommended by Danish guidelines. Hyperparathyroidism was defined as PTH concentrations $>6.9 \mathrm{pmol} / \mathrm{L}$, which is the upper reference limit used in Danish laboratories.

For analyses including hours spent outdoors, we only included workers who participated from April throughout September (N=227) where UVB exposure induces production of vitamin D. We excluded 39 workers with missing information on either BMI, hours spent outdoors on or off work, leaving 186 workers for analysis (81 indoor workers, 44 outdoor workers, 46 rotating shift workers, and 15 permanent night workers).

\section{Blood samples}

Blood samples were drawn at participants' place of work and collected in tubes without anticoagulation for serum and EDTA tubes for plasma and stored at $5{ }^{\circ} \mathrm{C}$ until processed to separate serum and plasma. Most samples $(\mathrm{N}=407)$ were processed within 8 hours (mean 3 hours 48 minutes), 30 samples were processed 10-33 hours after collection, and 4 samples were processed 94 hours after collection due to technical problems. Samples were stored at $-80^{\circ} \mathrm{C}$ after processing.

\section{Biochemical analyses}

All biochemical analyses were carried out in September 2014. Serum concentrations of $25 \mathrm{OHD}\left(25(\mathrm{OH}) \mathrm{D}_{2}\right.$ and $25 \mathrm{OHD}_{3}$ ) were analyzed by isotope dilution liquid chromatography-tandem mass spectrometry (LC MS/MS) as described by Maunsell et al. (48). Calibrators were traceable to NIST SRM 972 (Chromsystems GmbH, Gräfeling, Germany). The coefficient of variation (CV) for $25 \mathrm{OHD}_{3}$ was $6.4 \%$ at concentration $66.1 \mathrm{nmol} / \mathrm{l}$ and $9.4 \%$ at $25.3 \mathrm{nmol} / \mathrm{l}$. Plasma PTH concentration was analyzed using an automated immune analyzer (Cobas 6000 E; Roche Diagnostics GmbH, Berlin, Germany). The CV was $3.3 \%$ and $2.7 \%$ at PTH concentrations of 7.7 and $26.6 \mathrm{pmol} / \mathrm{l}$, respectively. Standard laboratory methods were used for measurements of total calcium, creatinine, and albumin. The estimated glomerular filtration rate (eGFR) was calculated according to the Modification of Diet in Renal Disease (MDRD) study equation (49).

\section{Questionnaire}

The questionnaire included information on sex, age (years), pregnancy (yes/no), current occupation, time spent working outdoors in spring, summer, autumn, and winter (never, 1-4, 5-9, 10-19, 20-29, 30-39, $\geq 40$ hours/ week), height (centimeters), weight (kilograms), smoking (current/former/never), use of medication (yes/no), vitamin pill use (yes/no), vitamin D supplement use (no/
$10 \mu \mathrm{g} / 20 \mu \mathrm{g}$ or more or cod liver oil (yes/no), tanning bed use (weekly, monthly, never), consumption of fish and shell food (never, monthly, 1, 2-3, >4 meals/week).

\section{Light exposure assessment}

Participants wore a Philips Respironics Actiwatch Spectrum (Actiwatch) light recorder during a 7-day study period. The Actiwatch was placed outside clothes on the upper arm and recorded white light (lux) and activity every minute. Time spent outdoors was assessed as periods where the light intensity measured by the Actiwatch was $\geq 1000$ lux (50). Light measurements were considered invalid if the participants reported the Actiwatch was not worn or the Actiwatch recorded no physical activity for $\geq 20$ minutes. We excluded 270 work days (26.5\%) and 126 days off work $(25.3 \%)$ with $<80 \%$ valid light measurements between 07:00-19:00 hours. Light measurements were included from 748 work days and 373 days off work.

\section{Statistical analyses}

Data was presented as numbers (\%), means with standard deviations (SD), or medians with interquartile ( $25^{\text {th }}-75$ th percentiles) ranges (IQR). Concentrations of 25OHD and PTH were naturally log transformed to obtain the best approximation with normal distributions. We tested the difference of 25OHD and PTH concentrations across seasons and job groups using the Kruskal-Wallis test.

We used multivariable linear regression to estimate the relative difference of serum $25 \mathrm{OHD}$ and plasma PTH concentrations between outdoor, rotating night workers and permanent night workers relative to indoor workers. Models were adjusted in two steps: Model 1 included season (January-March/April-June/July-September/ October-December). These differ from the traditional definitions of the seasons used in the questionnaire. Instead we classified season based on when the intensity of UVB begins (end of March) and ends (end of September) to induce vitamin D synthesis. Model 2 also included age (continuous), sex, socioeconomic status (SES) (white-collar worker / skilled blue-collar worker /unskilled blue-collar worker), current smoking (yes/ no), body mass index (BMI) (continuous), vitamin D supplements or cod liver oil (yes/no), birth control or hormone replacement therapy (yes/no), fish and shell food consumption ( $<1 \mathrm{meal} / \mathrm{week} / \geq 1 \mathrm{meal} / \mathrm{week})$, tanning bed use (ever/never), and time from blood sampling to storage. These potential confounders were identified a priori based on a review of the literature $(41,43,51-54)$ $(55,56)$. There was no interaction between job group and month of sampling or job group and sex, and the interaction terms were thus not included. 
We used logistic regression to estimate the odds ratio (OR) with $95 \%$ confidence interval $(95 \% \mathrm{CI})$ for vitamin $\mathrm{D}$ insufficiency $(<50 \mathrm{nmol} / \mathrm{L})$ and hyperparathyroidism $(>6.9 \mathrm{pmol} / \mathrm{L})$. These analyses included the same covariates as in the linear regression models.

Sensitivity analyses with a reference group of only indoor workers who reported never working outdoors was also conducted. To study a possible effect of sex, sensitivity analyses of the logistic and linear regression models were carried out stratified by sex.

In linear regression analyses of the effect of time spent outdoors on 250HD concentration, we only included the 186 workers who participated from AprilSeptember. We conducted three linear regression models (1); job group only (2) outdoor hours on work days and days off work and (3) job group and outdoor hours on work days and days off work. These analyses were adjusted for month of sampling; otherwise covariates were similar to the previous analyses.

All analyses were carried out using STATA 13.0 (StataCorp LP, College Station, TX, USA).

\section{Results}

Prevalence of smoking was highest among outdoor and permanent night workers (table 1). Use of vitamin D supplements was most prevalent among rotating shift and permanent night workers and least prevalent among outdoor workers. Fish and shell food consumption was lowest among permanent night workers. Indoor workers mainly participated from April-June, rotating night workers from October to December, while no permanent

Table 1. Characteristics of the population. [SD=standard deviation.]

\begin{tabular}{|c|c|c|c|c|c|c|c|c|c|c|c|c|c|c|c|c|}
\hline \multirow[t]{2}{*}{ Characteristics } & \multicolumn{4}{|c|}{ Indoor workers ( $\mathrm{N}=162)$} & \multicolumn{4}{|c|}{ Outdoor workers ( $\mathrm{N}=112)$} & \multicolumn{4}{|c|}{ Rotating shift workers $(\mathrm{N}=118)$} & \multicolumn{4}{|c|}{ Permanent night workers $\mathrm{N}=33$} \\
\hline & $\mathrm{N}$ & $\%$ & Mean & SD & $\mathrm{N}$ & $\%$ & Mean & SD & $\mathrm{N}$ & $\%$ & Mean & SD & $\mathrm{N}$ & $\%$ & Mean & SD \\
\hline Age & & & 45.3 & 11.0 & & & 40.8 & 12.6 & & & 39.3 & 9.3 & & & 44.9 & 8.6 \\
\hline Body mass index ${ }^{a}$ & & & 24.0 & 3.8 & & & 25.8 & 4.8 & & & 24.7 & 4.6 & & & 25.7 & 3.2 \\
\hline \multicolumn{17}{|l|}{ Gender } \\
\hline Female & 123 & 75.9 & & & 58 & 51.8 & & & 113 & 96.3 & & & 17 & 51.5 & & \\
\hline Male & 39 & 24.1 & & & 54 & 48.2 & & & 5 & 4.2 & & & 16 & 48.5 & & \\
\hline \multicolumn{17}{|l|}{ Socioeconomic status } \\
\hline White-collar worker & 135 & 83.3 & & & 64 & 57.1 & & & 116 & 98.3 & & & 14 & 42.4 & & \\
\hline Skilled blue-collar worker & 19 & 11.7 & & & 45 & 40.2 & & & 2 & 1.7 & & & 12 & 36.4 & & \\
\hline Unskilled blue-collar worker & 8 & 5.0 & & & 3 & 2.7 & & & 0 & 0.0 & & & 7 & 21.2 & & \\
\hline \multicolumn{17}{|l|}{ Current smoking } \\
\hline No & 141 & 87.0 & & & 82 & 73.2 & & & 105 & 89.0 & & & 24 & 72.7 & & \\
\hline Yes & 21 & 13.0 & & & 30 & 26.8 & & & 13 & 11.0 & & & 9 & 27.3 & & \\
\hline \multicolumn{17}{|l|}{ Supplementary vitamin D use ${ }^{\text {b }}$} \\
\hline No & 103 & 63.6 & & & 79 & 70.5 & & & 72 & 61.0 & & & 19 & 57.6 & & \\
\hline Yes & 59 & 36.4 & & & 33 & 29.5 & & & 46 & 39.0 & & & 14 & 42.4 & & \\
\hline \multicolumn{17}{|l|}{ Oestrogen use ${ }^{c}$} \\
\hline No & 157 & 96.9 & & & 110 & 98.2 & & & 107 & 90.7 & & & 32 & 97.0 & & \\
\hline Yes & 5 & 3.1 & & & 2 & 1.8 & & & 11 & 9.3 & & & 1 & 3.0 & & \\
\hline \multicolumn{17}{|l|}{ Fish and shell food } \\
\hline <1 meal/week & 60 & 37.0 & & & 42 & 37.5 & & & 48 & 40.7 & & & 18 & 54.6 & & \\
\hline$\geq 1$ meal/week & 102 & 63.0 & & & 70 & 62.5 & & & 70 & 59.3 & & & 15 & 45.5 & & \\
\hline \multicolumn{17}{|l|}{ Tanning bed use } \\
\hline Never & 158 & 97.5 & & & 107 & 95.5 & & & 111 & 94.0 & & & 30 & 90.9 & & \\
\hline Ever & 4 & 2.5 & & & 5 & 4.5 & & & 7 & 6.0 & & & 3 & 9.1 & & \\
\hline \multicolumn{17}{|l|}{ Season } \\
\hline January-March & 45 & 27.8 & & & 32 & 28.6 & & & 15 & 12.7 & & & 7 & 21.2 & & \\
\hline April-June & 73 & 45.1 & & & 36 & 32.1 & & & 39 & 33.1 & & & 20 & 60.6 & & \\
\hline July-September & 20 & 12.4 & & & 23 & 20.5 & & & 16 & 13.6 & & & 0 & 0.0 & & \\
\hline October-December & 24 & 14.8 & & & 21 & 18.8 & & & 48 & 40.6 & & & 6 & 18.2 & & \\
\hline \multicolumn{17}{|l|}{$\begin{array}{l}\text { Hours from blood sampling } \\
\text { to storage }\end{array}$} \\
\hline $0-24$ & 162 & 100 & & & 112 & 100 & & & 111 & 94.1 & & & 22 & 66.6 & & \\
\hline$>24$ & 0 & 0 & & & 0 & 0 & & & 7 & 5.9 & & & 11 & 33.3 & & \\
\hline \multicolumn{17}{|l|}{ Minutes outdoor/day d, e } \\
\hline Work days & 81 & & 147 & 89 & 44 & & 261 & 120 & 46 & & 107 & 68 & 15 & & 122 & 59 \\
\hline Days off & 81 & & 186 & 117 & 44 & & 182 & 113 & 46 & & 190 & 105 & 15 & & 152 & 92 \\
\hline
\end{tabular}


night workers participated July-September. Outdoor workers' participation was more equally distributed across seasons. Time from blood sampling to storage $>24$ hours in $33 \%$ of the permanent night workers while this was not the case for any indoor or outdoor workers. In the sub-population of workers participating from April-September, permanent night workers had a higher mean BMI [26.5 (SD 3.3) kg/m²] than indoor [24.1 (SD $\left.3.8) \mathrm{kg} / \mathrm{m}^{2}\right]$, outdoor [ $\left.25.4(\mathrm{SD} 4.8) \mathrm{kg} / \mathrm{m}^{2}\right]$, and rotating night workers [25.1 (SD 5.0) kg/m²]. Otherwise, sociodemographic characteristics were equivalent to the total population. In the sub-population, outdoor workers spent the longest time and permanent night workers the shortest time outdoors on work days. Permanent night workers also spent the shortest time outdoors on days off, but exposure in the other three groups was comparable.

Table 2 shows median 25OHD and PTH concentrations and prevalence of vitamin D insufficiency and hyperparathyroidism by job group and season. Within all job groups, 25OHD concentrations were highest and prevalence of vitamin D insufficiency lowest during JulySeptember (no measurements available from permanent night workers). The prevalence of vitamin $\mathrm{D}$ insufficiency was highest from January-March (56.6\%) and lowest from July-September (3.6\%). From July-September and October-December, indoor workers had higher median 25OHD concentrations $(95.8$ and $68.8 \mathrm{nmol} / \mathrm{L}$, respectively) than outdoor workers (78.8 and $58.8 \mathrm{nmol} / \mathrm{L}$, respectively). Otherwise indoor, outdoor and rotating night workers had comparable 25OHD concentrations. From January-March and April-June, permanent night workers had significantly lower median 25OHD concentrations than the other job groups $(19.2$ and $36.4 \mathrm{nmol} / \mathrm{L}$, respectively). PTH concentrations did not vary significantly within the job groups across seasons.

Table 3 presents results from the multivariable linear regression model of the relative difference in 25OHD and PTH concentrations between the four job groups. Outdoor workers had $4.5 \%$ (95\% CI -6.1-14.1) lower and permanent night workers a $28.4 \%$ (95\% CI 11.1 $36.1 \%$ ) lower 25OHD concentration than indoor workers in the season-adjusted analyses. When also adjusting for use of vitamin supplements and other expected predictors of 25OHD and PTH concentrations, outdoor workers showed a $2.5 \%(-74 .-13.4)$ higher 25OHD concentration than indoor workers, while the result for permanent night workers only changed slightly. Rotating night workers $25 \mathrm{OHD}$ and PTH concentrations did not differ from indoor workers in either model.

Analyses of PTH concentration adjusted for season showed a $23.6 \%(95 \%$ CI 9.2-39.8) higher concentration among the permanent night workers. When further adjusted the difference attenuated to $14.5 \%(95 \% \mathrm{CI}$ $0.1-31.1)$. Outdoor workers had 7.1\% (95\% CI -0.614.2) lower PTH concentrations than indoor workers adjusted for season. After adjustment for all confounders the difference was $7.5 \%$ (95\% CI -0.5-14.9). However, results were not significant. Otherwise limited differences were seen between the four job groups.

Table 4 presents job groups and OR for vitamin D insufficiency and hyperparathyroidism. Permanent night workers had a four-fold [OR 4.55, 95\% CI 1.39-14.94) higher odds of vitamin D insufficiency and outdoor workers tended to have lower [OR $0.30,95 \%$ CI 0.08 1.07) odds of hyperparathyroidism and perhaps also of vitamin D insufficiency (OR 0.85, 95\% CI 0.42-1.70)

Table 2. Median serum 25-hydroxyvitamin D (250HD) concentration, parathyroid hormone (PTH) concentration in plasma and percentage with vitamin $D$ insufficiency $\left(<50 \mathrm{nmol} / \mathrm{L}\right.$ ) and hyperparathyroidism ( $>6.9 \mathrm{pmol} / \mathrm{L}$ ) by season and job group with interquartile $\left(25-75^{\text {th }}\right.$ percentile) range (IQR) (IQR) and P-values for any difference between groups and seasons among 425 indoor, outdoor and night workers. [Prev=prevalence.]

\begin{tabular}{|c|c|c|c|c|c|c|c|c|c|c|c|c|c|c|c|c|c|c|}
\hline \multirow[t]{3}{*}{ Season } & \multicolumn{4}{|c|}{$\begin{array}{l}\text { Indoor workers } \\
\qquad(N=162)\end{array}$} & \multicolumn{4}{|c|}{$\begin{array}{l}\text { Outdoor workers } \\
\qquad(\mathrm{N}=112)\end{array}$} & \multicolumn{4}{|c|}{$\begin{array}{l}\text { Rotating night workers } \\
\qquad(\mathrm{N}=118)\end{array}$} & \multicolumn{4}{|c|}{$\begin{array}{l}\text { Permanent night workers } \\
\qquad(\mathrm{N}=33)\end{array}$} & \multicolumn{2}{|c|}{ P-value } \\
\hline & \multirow[b]{2}{*}{$\mathrm{N}$} & \multicolumn{2}{|c|}{ Concentration } & \multirow{2}{*}{$\frac{\text { Prev }^{\mathrm{a}}}{\%}$} & \multirow[b]{2}{*}{$\mathrm{N}$} & \multicolumn{2}{|c|}{ Concentration } & \multirow{2}{*}{$\frac{\text { Prev }^{a}}{\%}$} & \multirow[b]{2}{*}{$\mathrm{N}$} & \multicolumn{2}{|c|}{ Concentration } & \multirow{2}{*}{$\frac{\text { Prev }^{a}}{\%}$} & \multirow[b]{2}{*}{$\mathrm{N}$} & \multicolumn{2}{|c|}{ Concentration } & \multirow{2}{*}{$\frac{\text { Prev }^{a}}{\%}$} & \multirow[t]{2}{*}{ Conc. } & \multirow[t]{2}{*}{ Prev $^{a}$} \\
\hline & & Median & IQR & & & Median & IQR & & & Median & IQR & & & Median & IQR & & & \\
\hline \multicolumn{19}{|l|}{$\begin{array}{l}250 \mathrm{HD} \\
\text { (nmol/L) }\end{array}$} \\
\hline Jan-Mar & 45 & 46.9 & $28.5-64.7$ & 55.6 & 32 & 48.8 & $31.7-64.5$ & 56.3 & 15 & 48.03 & $37.4-62.8$ & 53.3 & 7 & 19.2 & $11.3-81.7$ & 71.4 & 0.575 & 0.872 \\
\hline Apr-June & 73 & 58.6 & $43.6-77.5$ & 37.0 & 25 & 58.8 & $40.3-73.9$ & 36.1 & 39 & 58.1 & $46.9-80.3$ & 33.3 & 20 & 36.4 & $27.8-47.6$ & 80.0 & 0.008 & 0.016 \\
\hline July-Sept & 20 & 95.8 & $78.3-105.5$ & 0.0 & 26 & 78.4 & $61.9-92.4$ & 8.7 & 16 & 84.7 & $72.7-94.6$ & 0.0 & 0 & & & & 0.082 & 0.203 \\
\hline Oct-Dec & 24 & 68.8 & $57.8-81.2$ & 16.7 & 26 & 56.5 & $50.1-70.8$ & 23.8 & 48 & 68.3 & $44.1-91.4$ & 29.2 & 6 & 76.6 & $69.8-83.7$ & 16.7 & 0.204 & 0.836 \\
\hline$P$-value d & & $<0.001$ & & $<0.001$ & & $<0.001$ & & 0.002 & & 0.001 & & 0.012 & & 0.050 & & $<0.001$ & & \\
\hline \multicolumn{19}{|c|}{ PTH (pmol/L) } \\
\hline Jan-Mar & 45 & 4.6 & $3.6-5.7$ & 13.3 & 32 & 3.9 & $3.7-4.8$ & 3.2 & 15 & 3.5 & $3.4-4.2$ & 0.0 & 7 & 4.8 & $4.0-6.3$ & 14.3 & 0.071 & 0.225 \\
\hline Apr-June & 72 & 4.5 & $3.4-5.6$ & 9.6 & 36 & 4.1 & $3.5-5.1$ & 0.0 & 39 & 4.4 & $3.6-5.3$ & 10.3 & 20 & 5.7 & $4.6-6.3$ & 15.0 & 0.025 & 0.191 \\
\hline July-Sept & 20 & 4.4 & $3.6-5.0$ & 0.0 & 23 & 4.1 & $3.4-4.9$ & 4.4 & 16 & 4.7 & $3.6-5.8$ & 18.8 & 0 & & & & 0.513 & 0.074 \\
\hline Oct-Dec & 24 & 4.1 & $3.4-5.5$ & 4.2 & 21 & 4.5 & $3.6-6.1$ & 9.5 & 48 & 4.6 & $3.5-5.6$ & 8.3 & 6 & 5.5 & $4.6-7.2$ & 33.3 & 0.224 & 0.175 \\
\hline $\mathrm{P}$-value ${ }^{\mathrm{d}}$ & & 0.726 & & 0.282 & & 0.573 & & 0.318 & & 0.201 & & 0.349 & & 0.691 & & 0.577 & & \\
\hline
\end{tabular}

a Prevalence of vitamin vitamin D insufficiency ( $<50 \mathrm{nmol} / \mathrm{L}$ ) and hyperparathyroidism ( $>6.9 \mathrm{pmol} / \mathrm{L})$.

${ }^{\mathrm{b}}$ Kruskal-Wallis test of any difference in concentrations between job groups.

c Kruskal-Wallis test of any difference in prevalence of vitamin D insufficiency/hyperthyroidism between job groups.

d Kruskal-Wallis test of any difference between seasons. 
Table 3. Relative differences (\%) in serum 25-hydroxyvitamin D (250HD) and parathyroid hormone (PTH) concentrations in plasma between 425 outdoor, rotating night, permanent night and indoor workers. [95\% $\mathrm{Cl}=95 \%$ confidence interval.]

\begin{tabular}{|c|c|c|c|c|c|}
\hline \multirow[t]{2}{*}{ Typeof worker group } & \multirow[t]{2}{*}{$\mathrm{N}$} & \multicolumn{2}{|c|}{ Model $1^{\text {a }}$} & \multicolumn{2}{|c|}{ Model $2^{\mathrm{b}}$} \\
\hline & & $\%$ Difference & $95 \% \mathrm{Cl}$ & $\%$ Difference & $95 \% \mathrm{Cl}$ \\
\hline \multicolumn{6}{|l|}{$250 \mathrm{HD}$} \\
\hline Indoor workers & 162 & 0.0 & Reference & 0.0 & Reference \\
\hline Outdoor workers & 112 & -4.5 & $-14.1-6.1$ & 2.5 & $-7.4-13.4$ \\
\hline Rotating night workers & 118 & -1.9 & $-11.8-9.1$ & -5.6 & $-14.8-4.4$ \\
\hline Permanent night workers & 33 & -28.4 & $-39.2--15.7$ & -25.3 & $-36.6--11.9$ \\
\hline \multicolumn{6}{|l|}{ PTH } \\
\hline Indoor workers & 161 & 0.0 & Reference & 0.0 & Reference \\
\hline Outdoor workers & 112 & -7.1 & $-14.2-0.6$ & -7.5 & $-14.9-0.5$ \\
\hline Rotating night workers & 118 & -1.3 & $-8.9-7.0$ & 0.7 & $-7.3-9.4$ \\
\hline Permanent night workers & 33 & 23.6 & $9.2-39.8$ & 14.5 & $0.1-31.1$ \\
\hline
\end{tabular}

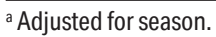

${ }^{b}$ Adjusted for season, sex, age, socioeconomic status, use of vitamin D supplements, use of birth control or hormone replacement therapy, body mass index, current smoking, fish and shell food consumption, use of sunbed and hours from blood sampling to freezing.

Table 4. Risk of vitamin D insufficiency (<50 nmol/L) or hyperparathyroidism $(>6.9 \mathrm{pmol} / \mathrm{L})$ in outdoor and night workers relative to indoor workers among 425 workers. [OR=odds ratio; $\mathrm{Cl}=$ confidence interval]

\begin{tabular}{|c|c|c|c|c|c|}
\hline \multirow{2}{*}{$\begin{array}{l}\text { Type of worker } \\
\text { group }\end{array}$} & \multirow[t]{2}{*}{$\mathrm{N}$} & \multicolumn{2}{|c|}{ Model 1 a } & \multicolumn{2}{|c|}{ Model 2b } \\
\hline & & $\mathrm{OR}$ & $95 \% \mathrm{Cl}$ & OR & $95 \% \mathrm{Cl}$ \\
\hline \multicolumn{6}{|c|}{ Vitamin D insufficiency } \\
\hline Indoor & 162 & 1.00 & Reference & 1.00 & Reference \\
\hline Outdoor & 112 & 1.15 & $0.66-1.99$ & 0.85 & $0.42-1.70$ \\
\hline Rotating night & 118 & 1.11 & $0.63-1.95$ & 1.25 & $0.61-2.56$ \\
\hline Permanent night & 33 & 3.61 & $1.59-8.20$ & 4.55 & $1.39-14.94$ \\
\hline \multicolumn{6}{|l|}{ Hyperparathyroidism } \\
\hline Indoor & 161 & 1.00 & Reference & 1.00 & Reference \\
\hline Outdoor & 112 & 0.39 & $0.12-1.21$ & 0.30 & $0.08-1.07$ \\
\hline Rotating night & 118 & 1.06 & $0.45-2.51$ & 1.30 & $0.49-3.48$ \\
\hline Permanent night & 33 & 2.37 & $0.83-6.81$ & 2.25 & $0.61-8.22$ \\
\hline
\end{tabular}

${ }^{a}$ Adjusted for season.

${ }^{\mathrm{b}}$ Adjusted for season, sex, age, socioeconomic status, use of vitamin D supplements, use of birth control or hormone replacement therapy, body mass index, current smoking, fish and shell food consumption, use of sunbed and hours from blood sampling to freezing.

compared with indoor workers.

Table 5 presents the relative difference $(\%)$ in 25OHD concentrations between job groups and per hour spent outdoors in the sub-population (workers participating from April throughout September). The adjusted model of job groups not including variables for outdoor hours showed $8.5 \% \%$ (95\% CI -5.6-24.6) higher concentration of 25OHD among outdoor workers and 6.6\% (95\% CI -18.4-6.9) and 15.6\% (95\% CI -33.6-7.4) lower concentrations among rotating and permanent night workers compared with indoor workers. The adjusted model of hours spent outdoor showed a $5.2 \%(95 \%$ CI 1.1-9.5) increase in 25OHD concentrations per hour spent outdoors on work days but only a limited increase by hours spent outdoors on days off. The final model that included outdoor hours and job group showed attenuated estimates for outdoor and permanent night workers compared with the model that did not include outdoor hours, while the effect for rotating night workers was limited.

PTH concentrations did not change by number of outdoor hours/day (data not shown).

Sensitivity analyses with indoor worker who never worked outdoors and analyses stratified by sex supported the main results.

\section{Discussion}

In the present cross-sectional study, permanent night workers had lower 25OHD and higher PTH concentrations than indoor workers. Outdoor workers tended to have a higher 25OHD concentration during summer and a lower PTH concentration irrespective of season than indoor workers. Workers with rotating night work had comparable 25OHD and PTH concentrations with indoor workers. 25OHD concentrations increased significantly by hours spent outdoors on workdays from April to September. The observed differences between permanent night workers, outdoor workers and indoor workers were significantly reduced in models that included time spent outdoors. This indicates that it was a significant predictor for the differences observed between the job groups.

In total, $151(35.5 \%)$ participants had vitamin $\mathrm{D}$ insufficiency in terms of 25OHD concentrations $<50$ $\mathrm{nmol} / \mathrm{L}$. As expected, prevalence was highest from January-March (56.6\%), lowest from July-September $3.6 \%$ and comparable to previous findings among healthy Danes $(41,42,57)$. Among indoor workers, the prevalence of vitamin $\mathrm{D}$ insufficiency was lower than in previous studies $(29,33,58)$, but $25 \mathrm{OHD}$ concentrations were comparable with most previous studies (27-29, $31,33,58,59)$ though mean $25 \mathrm{OHD}$ concentrations during the summer were lower in some of the studies $(27,29,35,58)$. 
Table 5. Relative difference (\%) in 25-hydroxyvitamin D concentrations with and without adjustment for hours spent outdoor/day a among 186 workers participating from April to September. [Cl=confidence interval.]

\begin{tabular}{|c|c|c|c|c|c|c|c|}
\hline \multirow[t]{2}{*}{ Variables (\% difference) } & \multirow[t]{2}{*}{$\mathrm{N}$} & \multicolumn{2}{|c|}{$\begin{array}{c}\text { Model with } \\
\text { job group only }{ }^{b}\end{array}$} & \multicolumn{2}{|c|}{$\begin{array}{c}\text { Model with } \\
\text { outdoor hours only }\end{array}$} & \multicolumn{2}{|c|}{$\begin{array}{c}\text { Model with } \\
\text { job group and outdoor hours }{ }^{b}\end{array}$} \\
\hline & & Estimate & $95 \% \mathrm{Cl}$ & Estimate & $95 \% \mathrm{Cl}$ & Estimate & $95 \% \mathrm{Cl}$ \\
\hline \multicolumn{8}{|l|}{ Type of worker group } \\
\hline Indoor & 81 & 0.0 & Reference & & & 0.0 & Reference \\
\hline Outdoor & 44 & 8.5 & $-5.6-24.6$ & & & 0.3 & $-13.5-16.3$ \\
\hline Rotating night & 46 & -6.6 & $-18.4-6.9$ & & & -4.0 & $-16.1-9.9$ \\
\hline Permanent night & 15 & -15.6 & $-33.6-7.4$ & & & -11.2 & $-30.0-12.7$ \\
\hline \multicolumn{8}{|c|}{$\begin{array}{l}\text { Outdoor hours }{ }^{a} / \text { day } \\
\text { (\% difference per hour/day) }\end{array}$} \\
\hline Work days & 186 & & & 5.8 & $2.3-9.5$ & 5.2 & $1.1-9.5$ \\
\hline Days off & 186 & & & 0.9 & $-2.1-4.0$ & 1.0 & $-2.1-4.1$ \\
\hline
\end{tabular}

In contrast to most previous findings, the outdoor workers in the present study did not have higher 25OHD concentrations than indoor workers all year round but only during the summer (26-28). One explanation for this may be that outdoor workers in our study spent shorter time outdoors during summer (4.5 hours on work days according to the light recordings). Our findings are, however, in line with a recent Danish study (29) reporting similar 25OHD concentrations in outdoor working farmers and their indoor working spouses.

In accordance with our results, 25OHD concentrations did not differ between indoor and rotating night workers in some previous studies $(34,35)$, but $25 \mathrm{OHD}$ concentrations were lower among rotating night workers in other studies $(31,33)$. In contrast to our findings the only previous study on permanent night workers of both sexes found similar 25OHD concentrations among day and night workers (34). However this study was carried out in South Korea, where lifestyle and UVB intensity differs from Denmark.

Average PTH concentrations were higher among permanent night workers and lower among outdoor workers compared to indoor workers; this underpins both the adverse and positive effects of 25OHD seen for these two job groups. To our knowledge, the association between PTH concentrations and day and night work has not previously been studied.

Despite spending more time outdoors, outdoor workers had similar 250HD concentrations as indoor workers around the year. However, the effect estimate was higher in the summer, though not statistically significant. Outdoor workers had higher BMI, were more likely to be smokers, fewer used vitamin D supplements, and had lower socioeconomic status. Before adjustment for co-variates outdoor workers had lower 25OHD concentrations and higher odds of vitamin D insufficiency than indoor workers. After adjustment outdoor workers had higher 25OHD concentrations and lower risk of vitamin
D insufficiency. Though all results were non-significant, this indicates that a poorer lifestyle among outdoor workers is counteracted by outdoor work. This is further supported by the significant association between hours spent outdoor on work days and 25OHD concentrations. However, we were not able to demonstrate the hypothesized difference in 25OHD concentration between indoor and outdoor workers. During the past decade a lot of focus has been put on skin cancer, and this may have resulted in outdoor workers protecting themselves against the sun with cloth and sunscreen resulting in less vitamin D production during work hours. Child care workers comprised a large percentage of the outdoor workers, and those working with the youngest kids are likely to work in the shade, as most playgrounds are placed to protect the children against the sun. Another industry represented in the outdoor work group is craftsmen, who tend to start work around 5-6 am during the summer and get off work early in the afternoon. During early morning hours, UVB is not intense enough to induce vitamin $\mathrm{D}$ production and the temperature is still low and less skin is exposed. This may cause lower total occupational UVB exposure and contribute to the lack of a difference. Another possible explanation is that high UVB exposure can degrade newly produced vitamin D present in the skin, and exposure to UVB therefore not results in 25OHD production (60). The outdoor workers reported working between 10-39 hours of outdoor/week and were compared to indoor workers who reported 0-9 hour's outdoor work/week. Lack of exposure contrast could also explain the similar 25OHD concentrations; however sensitivity analyses where only indoor workers never working outdoors were included were in line with main results.

The higher (non-significant) 25OHD concentrations observed the sub-population of outdoor workers participating through the month where UVB induces vitamin $\mathrm{D}$ production may indicate a positive effect of outdoor 
work during summer, which did not last throughout the year. However, there was no statistical interaction between job group and season in the full population. The lack of an interaction may indicate that the higher 25OHD observed during the summer is a chance finding, but it may also owe to lack of statistical power.

Among rotating night workers, 25OHD and PTH concentrations did not differ from indoor workers; this is in line with some $(34,35)$ but not all previous studies $(31,33)$. The rotating night workers were mostly women whereas the study by Romano et al only included males (31) and Munter et al studied a mixed population (33). The rotating shift workers in this study were mainly healthcare workers, who may have a healthier vitamin D lifestyle than factory workers, which counteracts the lower exposure to daylight on work days. The majority of the permanent night workers in the present study were factory workers. Compared to the rotating night workers they had a higher BMI, lower SES, were more likely to smoke and less likely to eat fish. However the prevalence of supplementary vitamin D use were similar to rotating night worker's and the prevalence of sunbed use higher, but all over this supports a poorer lifestyle among factory workers. The lack of a difference between the rotating night workers and day workers may also owe to frequency of night shifts, an information lacking in the present study. If numbers of night shifts are few, the overall difference in UVB exposure may be too small to be reflected in 25OHD concentrations. As seen with outdoor workers, the results from the subpopulation were a little different. Rotating night workers had 6.6\% (95\% CI -6.9-18.4) lower 25OHD than indoor workers during the light half year. This may, as suggested for outdoor workers, be due to a transient effect of hours spent outdoors during the summer, but it may also be a chance finding.

The concentration of 25OHD increased with hours spent outdoors on summer days. Studies on self-reported time outdoor have reported both similar $(33,61)$ and conflicting results $(58,62)$. In contrast to our study, a Danish study among farmers only found an association between mean daily UVR dose on days off work, but not on work days (29). This finding could perhaps be explained by farmers currently spending much of the workdays inside tractors and other vehicles, where the measured UVR mainly consists of UVA radiation, which does not induce 25OHD synthesis. No association was found between hours spent outdoors and PTH concentrations, probably because of sufficient $25 \mathrm{OHD}$ production during the sunny part of the year and a maximal suppression of $\mathrm{PTH}$.

The threshold value of $50 \mathrm{nmol} / 1$ used to define vitamin $\mathrm{D}$ insufficiency is based on the $25 \mathrm{OHD}$ concentrations, where PTH start to increase in different populations (63). However, the relevant 25OHD concentrations for vitamin $\mathrm{D}$ insufficiency differ between individuals (43), as not all subjects with $25 \mathrm{OHD}<50 \mathrm{nmol} / \mathrm{L}$ show signs of vitamin D insufficient in terms of eg, elevated PTH concentrations. The optimal 25OHD concentration with respect to extra-skeletal diseases is unknown, but has been suggested to be $75 \mathrm{nmol} / \mathrm{l}$ (39). The implication would be a higher prevalence of participants with vitamin D concentrations that are harmful to health.

\section{Strengths and limitations}

The study was cross-sectional and results should be interpreted cautiously regarding causality. However, it is not very likely that vitamin D concentrations influenced participants' decision on whether to work during the day or night. Hours of outdoor work was self-reported and prone to recall bias, however this is not likely related to 25OHD or PTH concentration and misclassification would cause non-differential misclassification and bias towards null. Serum 25OHD and plasma PTH concentrations were measured with the most precise laboratory methods. We excluded subjects with medical conditions or treatment with drugs potentially affecting calcium homeostasis and vitamin D metabolism. Further, we used objective measures of light to assess time spent outdoors. We adjusted for a wide range of known predictors of vitamin D concentrations, but some residual confounding cannot be excluded. Oestrogen concentrations are an important predictor of 25OHD concentrations, we adjusted for use of exogenous oestrogen, but we did not have information on postmenopausal status or menstrual cycle. However, we adjusted for age which is closely related to postmenopausal status and menstrual cycle has been shown not to affect 25OHD (64).

\section{Concluding remarks}

Permanent night workers spent less time outdoors and had lower 25OHD and higher PTH concentrations than indoor workers. Outdoor workers spent more hours outdoors but 25OHD concentrations were similar to indoor workers. This was partly explained by a poorer lifestyle among outdoor workers. PTH and odds of hyperparathyroidism were lower among outdoor workers though not significant. Rotating night workers' 25OHD and PTH concentrations did not differ from indoor workers. The concentration of 25OHD increased by hours spent outdoor on workdays during summer, and differences between job groups were partly explained by differences in time spent outdoor. Clinicians should be aware that vitamin $\mathrm{D}$ insufficiency may be more prevalent among permanent night workers, and employers should consider the positive effects on 25OHD and PTH status by allowing their workers to spend time outdoors during work hours. 


\section{Acknowledgements}

We would like to thank all the participants in the study: Anja Jørgensen, Louise Brus Hesselvang, Anne Abildtrup, Inge Christensen, Dorrit Meincke, and Ulla Tegner for collection of data. Jesper Medom Vestergaard and Morten Frydenberg are thanked for their skillful help with data management and analysis. The Danish Working Environment Research Fund funded the study (02-2010-09).

\section{Declaration of interest}

All authors declare no conflicts of interest.

\section{References}

1. Holick MF. McCollum Award Lecture, 1994: vitamin D-new horizons for the 21st century. Am J Clin Nutr 1994 Oct;60(4):619-30. http://dx.doi.org/10.1093/ajcn/60.4.619.

2. Baeke F, Takiishi T, Korf H, Gysemans C, Mathieu C. Vitamin D: modulator of the immune system. Curr Opin Pharmacol 2010 Aug;10(4):482-96. http://dx.doi. org/10.1016/j.coph.2010.04.001.

3. Christakos S, Dhawan P, Verstuyf A, Verlinden L, Carmeliet G. Vitamin D: Metabolism, molecular mechanism of action, and pleiotropic effects. Physiol Rev 2016 Jan;96(1):365408. http://dx.doi.org/10.1152/physrev.00014.2015.

4. Holick MF. Vitamin D deficiency. N Engl J Med 2007 Jul;357(3):266-81. http://dx.doi.org/10.1056/ NEJMra070553.

5. van der Rhee H, Coebergh JW, de Vries E. Sunlight, vitamin $\mathrm{D}$ and the prevention of cancer: a systematic review of epidemiological studies. Eur J Cancer Prev 2009 Nov;18(6):458-75. http://dx.doi.org/10.1097/ CEJ.0b013e32832f9bb1.

6. Pilz S, Verheyen N, Grübler MR, Tomaschitz A, März W. Vitamin D and cardiovascular disease prevention. Nat Rev Cardiol 2016 Jul;13(7):404-17. http://dx.doi.org/10.1038/ nrcardio.2016.73.

7. Beveridge LA, Witham MD. Vitamin D and the cardiovascular system. Osteoporos Int 2013 Aug;24(8):216780. http://dx.doi.org/10.1007/s00198-013-2281-1.

8. Mathieu C. Vitamin D and diabetes: where do we stand? Diabetes Res Clin Pract 2015 May;108(2):201-9. http:// dx.doi.org/10.1016/j.diabres.2015.01.036.

9. Sundström P, Salzer J. Vitamin D and multiple sclerosisfrom epidemiology to prevention. Acta Neurol Scand 2015;132(199 S199):56-61. http://dx.doi.org/10.1111/ ane.12432.

10. Sicherer SH, Sampson HA. Food allergy: Epidemiology, pathogenesis, diagnosis, and treatment. J Allergy Clin
Immunol. 2014;133(2):291,307.e5.

11. Yuan X, Zhu C, Wang M, Mo F, Du W, Ma X. Night Shift Work Increases the Risks of Multiple Primary Cancers in Women: A Systematic Review and Meta-analysis of 61 Articles. Cancer Epidemiol Biomarkers Prev 2018 Jan;27(1):25-40. http://dx.doi.org/10.1158/1055-9965.EPI$17-0221$.

12. Hansen AB, Stayner L, Hansen J, Andersen ZJ. Night shift work and incidence of diabetes in the Danish Nurse Cohort. Occup Environ Med 2016 Apr;73(4):262-8. http://dx.doi. org/10.1136/oemed-2015-103342.

13. Gan Y, Yang C, Tong X, Sun H, Cong Y, Yin X et al. Shift work and diabetes mellitus: a meta-analysis of observational studies. Occup Environ Med 2015 Jan;72(1):72-8. http:// dx.doi.org/10.1136/oemed-2014-102150.

14. Vetter C, Dashti HS, Lane JM, Anderson SG, Schernhammer ES, Rutter MK et al. Night Shift Work, Genetic Risk, and Type 2 Diabetes in the UK Biobank. Diabetes Care 2018 Apr;41(4):762-9. http://dx.doi.org/10.2337/dc17-1933.

15. Feskanich D, Hankinson SE, Schernhammer ES. Nightshift work and fracture risk: the Nurses' Health Study. Osteoporos Int 2009 Apr;20(4):537-42. http://dx.doi.org/10.1007/ s00198-008-0729-5.

16. Karami S, Colt JS, Stewart PA, Schwartz K, Davis FG, Ruterbusch JJ et al. A case-control study of occupational sunlight exposure and renal cancer risk. Int J Cancer 2016 Apr;138(7):1626-33. http://dx.doi.org/10.1002/ijc.29902.

17. Grant WB. Role of solar UVB irradiance and smoking in cancer as inferred from cancer incidence rates by occupation in Nordic countries. Dermatoendocrinol 2012 Apr;4(2):20311. http://dx.doi.org/10.4161/derm.20965.

18. Freedman DM, Dosemeci M, McGlynn K. Sunlight and mortality from breast, ovarian, colon, prostate, and nonmelanoma skin cancer: a composite death certificate based case-control study. Occup Environ Med 2002 Apr;59(4):257-62. http://dx.doi.org/10.1136/oem.59.4.257.

19. Freedman DM, Dosemeci M, Alavanja MC. Mortality from multiple sclerosis and exposure to residential and occupational solar radiation: a case-control study based on death certificates. Occup Environ Med 2000 Jun;57(6):418 21. http://dx.doi.org/10.1136/oem.57.6.418.

20. Westberg M, Feychting M, Jonsson F, Nise G, Gustavsson P. Occupational exposure to UV light and mortality from multiple sclerosis. Am J Ind Med 2009 May;52(5):353-7. http://dx.doi.org/10.1002/ajim.20682.

21. Kenborg L, Lassen CF, Ritz B, Schernhammer ES, Hansen J, Gatto NM et al. Outdoor work and risk for Parkinson's disease: a population-based case-control study. Occup Environ Med 2011 Apr;68(4):273-8. http://dx.doi. org/10.1136/oem.2010.057448.

22. Kwon E, Gallagher LG, Searles Nielsen S, Franklin GM, Littell CT, Longstreth WT Jr et al. Parkinson's disease and history of outdoor occupation. Parkinsonism Relat Disord 2013 Dec;19(12):1164-6. http://dx.doi.org/10.1016/j. parkreldis.2013.08.014 
23. Shen L, Ji HF. Associations between Vitamin D Status, Supplementation, Outdoor Work and Risk of Parkinson's Disease: A Meta-Analysis Assessment. Nutrients 2015 Jun;7(6):4817-27. http://dx.doi.org/10.3390/nu7064817.

24. Fritschi L, Glass DC, Heyworth JS, Aronson K, Girschik J, Boyle T et al. Hypotheses for mechanisms linking shiftwork and cancer. Med Hypotheses 2011 Sep;77(3):430-6. http:// dx.doi.org/10.1016/j.mehy.2011.06.002.

25. Grant WB. Low vitamin D concentrations may contribute to the increased risk of diabetes mellitus related to shift work. Occup Environ Med. 2015 Feb;72(2):161. http://dx.doi. org/10.1136/oemed-2014-102578.

26. Devgun MS, Paterson CR, Johnson BE, Cohen C. Vitamin $\mathrm{D}$ nutrition in relation to season and occupation. Am J Clin Nutr 1981 Aug;34(8):1501-4. http://dx.doi.org/10.1093/ ajen/34.8.1501.

27. Azizi E, Pavlotsky F, Vered I, Kudish AI. Occupational exposure to solar UVB and seasonal monitoring of serum levels of 25-hydroxy vitamin D3: a case-control study. Photochem Photobiol 2009 Sep-Oct;85(5):1240-4. http:// dx.doi.org/10.1111/j.1751-1097.2009.00569.x.

28. Pazaitou-Panayiotou K, Papapetrou PD, Chrisoulidou A, Konstantinidou S, Doumala E, Georgiou E et al. Height, whole Body Surface Area, gender, working outdoors, and sunbathing in previous summer are important determinants of serum 25-hydroxyvitamin D levels. Exp Clin Endocrinol Diabetes 2012 Jan;120(1):14-22. http:// dx.doi.org/10.1055/s-0031-1285912.

29. Bodekær M, Petersen B, Thieden E, Philipsen PA, Heydenreich J, Olsen $\mathrm{P}$ et al. UVR exposure and vitamin $\mathrm{D}$ in a rural population. A study of outdoor working farmers, their spouses and children. Photochem Photobiol Sci 2014 Nov;13(11):1598-606. http://dx.doi.org/10.1039/ C4PP00188E.

30. Ward M, Berry DJ, Power C, Hyppönen E. Working patterns and vitamin D status in mid-life: a cross-sectional study of the 1958 British birth cohort. Occup Environ Med 2011 Dec;68(12):902-7. http://dx.doi.org/10.1136/ oem.2010.063479.

31. Romano A, Vigna L, Belluigi V, Conti DM, Barberi CE, Tomaino $\mathrm{L}$ et al. Shift work and serum $25-\mathrm{OH}$ vitamin D status among factory workers in Northern Italy: crosssectional study. Chronobiol Int 2015;32(6):842-7. http:// dx.doi.org/10.3109/07420528.2015.1048867.

32. Alefishat E, Abu Farha R. Determinants of vitamin d status among Jordanian employees: focus on the night shift effect. Int J Occup Med Environ Health 2016;29(5):859-70. http:// dx.doi.org/10.13075/ijomeh.1896.00657.

33. Munter G, Levi-Vineberg T, Sylvetsky N. Vitamin D deficiency among physicians: a comparison between hospitalists and community-based physicians. Osteoporos Int 2015 Jun;26(6):1673-6. http://dx.doi.org/10.1007/ s00198-015-3028-y.

34. Kim BK, Choi YJ, Chung YS. Other than daytime working is associated with lower bone mineral density: the Korea
National Health and Nutrition Examination Survey 2009. Calcif Tissue Int 2013 Dec;93(6):495-501. http://dx.doi. org/10.1007/s00223-013-9779-6.

35. Itoh H, Weng Z, Saito H, Ogawa Y, Nakayama K, Hasegawa-Ohira $\mathrm{M}$ et al. Association between night-shift work and serum 25-hydroxyvitamin D levels in Japanese male indoor workers: a cross-sectional study. Ind Health 2011;49(5):658-62. http://dx.doi.org/10.2486/indhealth. MS1271.

36. Glerup H, Mikkelsen K, Poulsen L, Hass E, Overbeck S, Thomsen $\mathrm{J}$ et al. Commonly recommended daily intake of vitamin $\mathrm{D}$ is not sufficient if sunlight exposure is limited [GBR]. J Intern Med 2000 Feb;247(2):260-8. http://dx.doi. org/10.1046/j.1365-2796.2000.00595.x.

37. Barger-Lux MJ, Heaney RP. Effects of above average summer sun exposure on serum 25-hydroxyvitamin D and calcium absorption. J Clin Endocrinol Metab 2002 Nov;87(11):4952-6. http://dx.doi.org/10.1210/jc.2002020636 .

38. Ross AC, Manson JE, Abrams SA, Aloia JF, Brannon PM, Clinton SK et al. The 2011 report on dietary reference intakes for calcium and vitamin D from the Institute of Medicine: what clinicians need to know. J Clin Endocrinol Metab 2011 Jan;96(1):53-8. http://dx.doi.org/10.1210/ jc. 2010-2704.

39. Holick MF, Binkley NC, Bischoff-Ferrari HA, Gordon CM, Hanley DA, Heaney RP et al.; Endocrine Society. Evaluation, treatment, and prevention of vitamin D deficiency: an Endocrine Society clinical practice guideline. J Clin Endocrinol Metab 2011 Jul;96(7):1911-30. http:// dx.doi.org/10.1210/jc.2011-0385.

40. Cashman KD. A review of vitamin D status and CVD. Proc Nutr Soc 2014 Feb;73(1):65-72. http://dx.doi.org/10.1017/ S0029665113003595.

41. Thuesen B, Husemoen L, Fenger M, Jakobsen J, Schwarz P, Toft $U$ et al. Determinants of vitamin D status in a general population of Danish adults. Bone 2012 Mar;50(3):605-10. http://dx.doi.org/10.1016/j.bone.2011.12.016.

42. Mosekilde L, Nielsen LR, Larsen ER, Moosgaard B, Heickendorff L. Vitamin D-mangel. Definition og praevalens i Danmark. [Vitamin D deficiency. Definition and prevalence in Denmark]. Ugeskr Laeger 2005 Jan;167(1):29-33.

43. Rejnmark L, Vestergaard P, Brot C, Mosekilde L. Increased fracture risk in normocalcemic postmenopausal women with high parathyroid hormone levels: a 16-year follow-up study. Calcif Tissue Int 2011 Mar;88(3):238-45. http://dx.doi. org/10.1007/s00223-010-9454-0.

44. van Ballegooijen AJ, Reinders I, Visser M, Brouwer IA. Parathyroid hormone and cardiovascular disease events: A systematic review and meta-analysis of prospective studies. Am Heart J. 2013 May;165(5):655,64, 664.e1-5.

45. Yang B, Lu C, Wu Q, Zhang J, Zhao H, Cao Y. Parathyroid hormone, cardiovascular and all-cause mortality: A metaanalysis. Clin Chim Acta 2016 Apr;455:154-60. http:// dx.doi.org/10.1016/j.cca.2016.01.034. 
46. Daugaard S, Garde AH, Bonde JP, Christoffersen J, Hansen AM, Markvart J et al. Night work, light exposure and melatonin on work days and days off. Chronobiol Int 2017;34(7):942-55. http://dx.doi.org/10.1080/07420528.20 17.1327867.

47. Stevens RG, Hansen J, Costa G, Haus E, Kauppinen T, Aronson KJ et al. Considerations of circadian impact for defining 'shift work' in cancer studies: IARC Working Group Report. Occup Environ Med 2011 Feb;68(2):154-62. http://dx.doi.org/10.1136/oem.2009.053512.

48. Maunsell Z, Wright DJ, Rainbow SJ. Routine isotope-dilution liquid chromatography-tandem mass spectrometry assay for simultaneous measurement of the 25-hydroxy metabolites of vitamins D2 and D3. Clin Chem 2005 Sep;51(9):1683-90. http://dx.doi.org/10.1373/clinchem.2005.052936.

49. Levey AS, Bosch JP, Lewis JB, Greene T, Rogers N, Roth D; Modification of Diet in Renal Disease Study Group. A more accurate method to estimate glomerular filtration rate from serum creatinine: a new prediction equation. Ann Intern Med 1999 Mar;130(6):461-70. http://dx.doi. org/10.7326/0003-4819-130-6-199903160-00002.

50. Figueiro MG, Steverson B, Heerwagen J, Kampschroer $\mathrm{K}$, Hunter CM, Gonzales K et al. The impact of daytime light exposures on sleep and mood in office workers. Sleep Health 2017 Jun;3(3):204-15. http://dx.doi.org/10.1016/j. sleh.2017.03.005.

51. Hirani V, Mosdøl A, Mishra G. Predictors of 25-hydroxyvitamin D status among adults in two British national surveys. Br J Nutr 2009 Mar;101(5):760-4. http:// dx.doi.org/10.1017/S0007114508023416.

52. Larose TL, Chen Y, Camargo CA Jr, Langhammer A, Romundstad P, Mai XM. Factors associated with vitamin D deficiency in a Norwegian population: the HUNT Study. J Epidemiol Community Health 2014 Feb;68(2):165-70. http://dx.doi.org/10.1136/jech-2013-202587.

53. Brock K, Huang WY, Fraser DR, Ke L, Tseng M, Stolzenberg-Solomon R, et al. Low vitamin D status is associated with physical inactivity, obesity and low vitamin D intake in a large US sample of healthy middle-aged men and women. J Steroid Biochem Mol Biol 2010 Jul;121(12):462-6. http://dx.doi.org/10.1016/j.jsbmb.2010.03.091.

54. Paik JM, Farwell WR, Taylor EN. Demographic, dietary, and serum factors and parathyroid hormone in the National Health and Nutrition Examination Survey. Osteoporos Int 2012 Jun;23(6):1727-36. http://dx.doi.org/10.1007/s00198011-1776-x.

55. Rejnmark L, Lauridsen AL, Brot C, Vestergaard P, Heickendorff L, Nexo E et al. Vitamin D and its binding protein Gc: long-term variability in peri- and postmenopausal women with and without hormone replacement therapy. Scand J Clin Lab Invest 2006;66(3):227-38. http://dx.doi. org/10.1080/00365510600570623.
56. Møller UK, Streym S, Jensen LT, Mosekilde L, Schoenmakers I, Nigdikar $\mathrm{S}$ et al. Increased plasma concentrations of vitamin D metabolites and vitamin D binding protein in women using hormonal contraceptives: a cross-sectional study. Nutrients 2013 Sep;5(9):3470-80. http://dx.doi.org/10.3390/nu5093470.

57. Lund B, Sørensen OH. Measurement of 25-hydroxyvitamin $\mathrm{D}$ in serum and its relation to sunshine, age and vitamin D intake in the Danish population. Scand J Clin Lab Invest 1979 Feb;39(1):23-30. http://dx.doi. org/10.3109/00365517909104935.

58. Cinar N, Harmanci A, Yildiz BO, Bayraktar M. Vitamin $\mathrm{D}$ status and seasonal changes in plasma concentrations of 25-hydroxyvitamin D in office workers in Ankara, Turkey. Eur J Intern Med 2014 Feb;25(2):197-201. http://dx.doi. org/10.1016/j.ejim.2013.11.004.

59. Itoh H, Mori I, Matsumoto Y, Maki S, Ogawa Y. Vitamin $\mathrm{D}$ deficiency and seasonal and inter-day variation in circulating 25-hydroxyvitamin D and parathyroid hormone levels in indoor daytime workers: a longitudinal study. Ind Health 2011;49(4):475-81. http://dx.doi.org/10.2486/ indhealth.MS1255.

60. Webb AR, DeCosta BR, Holick MF. Sunlight regulates the cutaneous production of vitamin D3 by causing its photodegradation. J Clin Endocrinol Metab 1989 May;68(5):882-7. http://dx.doi.org/10.1210/jcem-68-5-882.

61. Haney EM, Stadler D, Bliziotes MM. Vitamin D insufficiency in internal medicine residents. Calcif Tissue Int 2005 Jan;76(1):11-6. http://dx.doi.org/10.1007/s00223004-0025-0.

62. Wallingford SC, Jones G, Kobayashi LC, Grundy A, Miao $\mathrm{Q}$, Tranmer $\mathrm{J}$ et al. UV and dietary predictors of serum 25-hydroxyvitamin D concentrations among young shiftworking nurses and implications for bone density and skin cancer. Public Health Nutr 2014 Apr;17(4):772-9. http:// dx.doi.org/10.1017/S1368980013001754.

63. Lips P. Vitamin D deficiency and secondary hyperparathyroidism in the elderly: consequences for bone loss and fractures and therapeutic implications. Endocr Rev 2001 Aug;22(4):477-501. http://dx.doi.org/10.1210/ edrv.22.4.0437.

64. Franasiak JM, Wang X, Molinaro TA, Green K, Sun W, Werner MD et al. Free vitamin D does not vary through the follicular phase of the menstrual cycle. Endocrine 2016 Jul;53(1):322-6. http://dx.doi.org/10.1007/s12020-0160946-1.

Received for publication: 28 August 2017 